\title{
The Model Driven Decision Support System for Predicting the Major Pest in Onion (Allium Cepa L)
}

\author{
Fidel G. Patricio Jr${ }^{1}$, Maria Visitacion N. Gumabay ${ }^{2}$ \\ ${ }^{1}$ St.Paul University Philippines, Philippines, fgpatriciojr@gmail.com \\ ${ }^{2}$ St.Paul University Philippines, Philippines, mvgumabay@ spup.edu.ph
}

\begin{abstract}
There is worldwide demand for Alliums (onions), and their use is not limited to any climate or associated with any nationality.Alliums are eaten uniformly in limited amounts, and are used almost regularly in many households, especially as a seasoning for flavoring various dish varieties. Onion contains vitamins, carbohydrates and minimal amount proteins.
\end{abstract}

Producing onion crops is very important thus the management of its growth and production is equally as important. Considering climatic factors and pest occurrence, the production of onions is greatly affected. Phytophagous insects, plant disease, and weeds are major constrain in onion production. This study aims to provide a model and tool for the decision support system analyzing the relationship between pest thriving requirements, climatic data and onion pest susceptibility. An Android mobile application in predicting the occurrence of major pest in onions will be incorporated.

The descriptive and historical design will be used to collect and provide pertinent data to develop a Model-Driven Decision Support System for Predicting the Major Pest in Onion (Allium cepa L). Agile Methodology will be utilized in the development of the mobile application. The proponent will also use frequency count, percentage distribution, mean, ARIMA and matching algorithms to determine relationships in accordance with ISO25010 compliance.

This research will gather climatic data and match it with pest weather characteristics through a DSS creating a prediction and suggestion or intervention.

Using questionnaires, Farmers, IT experts and LGU will be asked to evaluate the effectiveness of the proposed android based app on the ISO/IEC 25010 Product Quality Questionnaire. This study will also recommend opportunities for improvement towards better climate adaptation, pest control and mitigation.

Key words: Allium, Allium Cepa, App, Crop, Onions, Pest Management, Weather Data, Climate Change, Climatic Data, Matching Algorithm, Pest, Mitigation, Decision Support System

\section{INTRODUCTION}

The Philippines is a tropical country and recognized as an onion-growing country from the Luzon to Mindanao. Onion is a versatile high-value crop that can be cultivated throughout the archipelago. Farmers tried and proven that they can earn more from cultivating "sibuyas" as they called it in Filipino particularly the red bulb variety. As a matter of fact, many farmers shifted from rice to onion to take advantage of growing demand for onions [5].

Yellow/brown, Red, and White are the common onion varieties. Onions composes of sugar, protein, fiber and low amounts of essential nutrients but mostly $89 \%$ water. Onion adds flavors to food without raising the calorie content [6].

Phytophagous insects, plant disease, and weeds are major constrain in onion production. The most important insect pests attacking onion include the armyworms (Spodoptera litura and S. exigua), Thrips (Thrips tabaci) and Leafminer (Liriomysa spp.) For the last two years in onion production, damage of armyworms is serious affecting almost all onion growing areas in Nueva Ecija and some areas in Pangasinan. Based on the latest data (from March to April 2017 of the provincial government, OPA-NE, May 2017), the total area infested was 1,076.74 hectares (out of 1,913.59 has planted) equivalent to $2.834 .97 \mathrm{MT}$ and translated to total yield loss amounted to Php 72,626,557.00 from the 11 affected municipalities. Among the municipalities of Nueva Ecija, the most infested areas were Sto. Domingo, Bongabon and Rizal [2].

In this study, the proponent incorporated Android mobile application in predicting the occurrence of major pest in onions. There are many studies conducted as well as occurrence reports regarding pests and diseases of onions, but there are no detailed studies that attempted to match such with climatic factors. This research gathered climatic data and match it with previous pest occurrence through a DSS based on predictive analytics.

\section{LITERATURE REVIEW}

Mobile phone becomes undeniably important tool in our everyday life and activities. Constant development and evolution means mobile phone is no longer just a 
Fidel G. Patricio Jr et al., International Journal of Advanced Trends in Computer Science and Engineering, 9(3), May - June 2020, 3450 - 3453

communication device. It can be a digital wallet, a pocket entrainment or a digital source of information. Individuals are using these new features to make their lives much easier and businesses are developing methods to use mobile phone to further reach their customers. Business owners have been using Decision Support Systems (DSS) to support in their decision making in any area of their business [4]. DSS would help business by expanding their product reach by delivering what the consumer needs by examining different sources of information [3].

The proponent developed a mobile based application to help farmers in combating pest infestation that can destroy their onion crop. It helps to identify and record the spread of the pest in their area [1]. The application can also have a significant impact on the way information is collected, stored, and accessed nationwide in the agricultural sector. Onion growers are continually encountering challenges producing quality and marketable produce while simultaneously dealing with biotic stresses. Phytophagous insects, plant diseases, and weeds are major constraints in onion production. The most important insect pests attacking onion include the armyworms (Spodoptera. exigua), Thrips (Thrips tabaci) and Leafminer (Liriomysa spp.) (Mishra et al., 2012). Moreover, onion growers are losing their production hugely because of fungal diseases. Among these are anthracnose/twister (Colletotrichum gloesporioidis), basal bulb rot (Fusarium oxysporum f. sp. cepae), and purple blotch (Alternaria porri).

The strategies for crop protection are related to the climatic conditions, considering that there is important relationship between climate, crops and pests [7]. A study conducted on integrated pest management activities (IPM) on olive crops based on climatic data creating a new decision-support system. In the said study, various and simultaneous use of agricultural protection techniques are used in IPM to control pests through an environmentally sound and economical approach.

\section{METHODOLOGY}

This paper implements various research designs as a strategy in integrating different components of the study in a logical and comprehensive way to ensure that the researcher addresses the identified problems. Such designs include descriptive, exploratory, historical, and AGILE methodology.

Descriptive Design. The proponent 's goal in this research was to provide answers to questions of who, what, where, where, and how in connection with the research topic. In particular, this research aims to obtain information about the current status of the conditions and to understand what happens in reference to variable pest and climatic conditions.

Historical Design. In implementing this research design, the proponent collected, verified and synthesized pieces of evidence from the past to establish facts to utilize in the DSS of this system. Secondary sources come from PAGASA and entomologists, such as the climatic and pest data that are used as evidence. These historical data are helpful especially in the trend analysis particular in the implementation of the Autoregressive Integrated Moving Average model (ARIMA). This study also utilized AGILE methodology in developing the system.

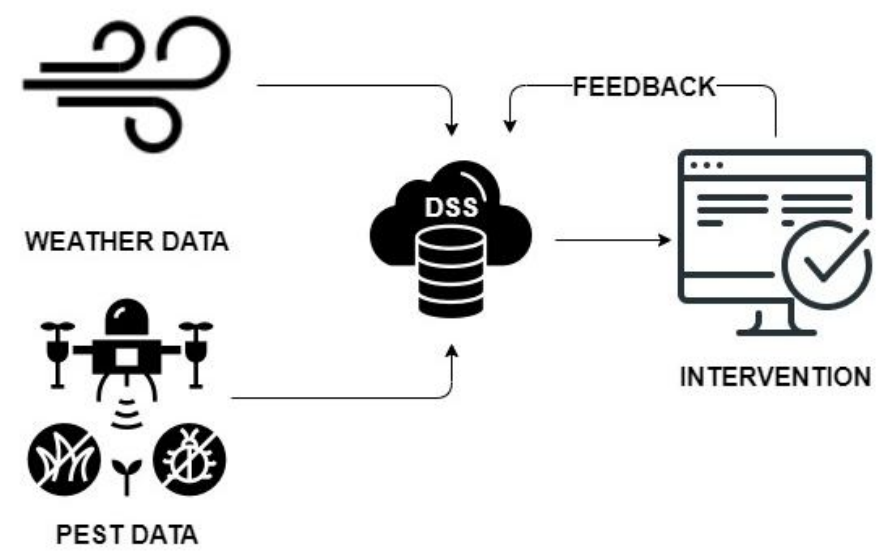

Figure 1: Climate-Pest DSS Model for Onion Farming

\subsection{Architectural Design}

Figure 2 shows the architectural framework in relation with DSS. Figure 1 shows the Climate-Pest DSS Model for Onion Farming, the decision support system established relationships between the above factors (Pest Data, Weather data and Intervention measures) and developed statistical models, creating a feasible model for pest forecast, suggested pesticide and the best time for plantation which will help farmers to produce onion crops efficiently and effectively manage pests. The DSS also particularly identify matching between pest thriving and onion growth stage, detecting what pest is more like to thrive in what stage. The forecasted weather is then stored in a data bank. The said forecast is matched with pest data and characteristics such as pest temperature requirement, rain and humidity requirement for thriving as well as the stage of their growth. Based on the matching of the forecast and pest data, the system then predicts the month of highest pest occurrence and possible interventions, after which such data will then be stored and serve as statistical data for a more accurate prediction in the future.

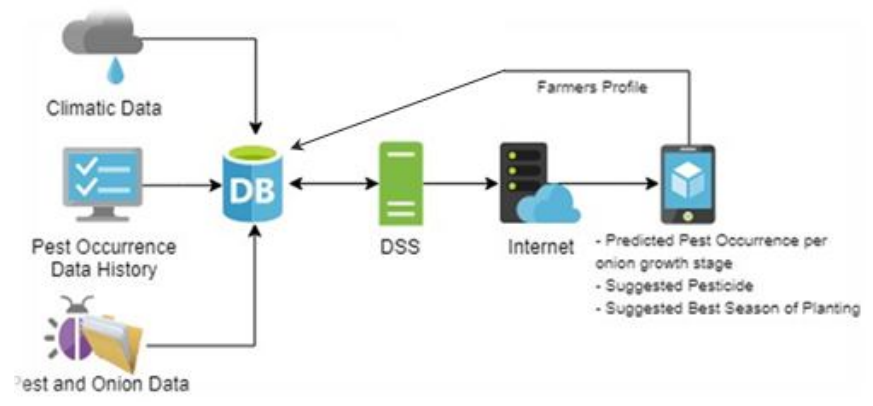

Figure 2: Architectural Framework Diagram 
Fidel G. Patricio Jr et al., International Journal of Advanced Trends in Computer Science and Engineering, 9(3), May - June 2020, 3450 - 3453

\section{RESULT AND DISCUSSION}

The results of the demographics, current common pests attacking onions and the degree of pest's infestation, onion vulnerability, forecasting model, significant predictors, the formulated algorithm model for prediction, and the extent of compliance of the developed tool to ISO 25010 software quality standards.

As per data gathered, Figure 3 shows the most common pests attacking onions are Leaf miners and Thrips having (rank 1) Armyworm and Onion Fly (rank 2), while anthracnose comes last.

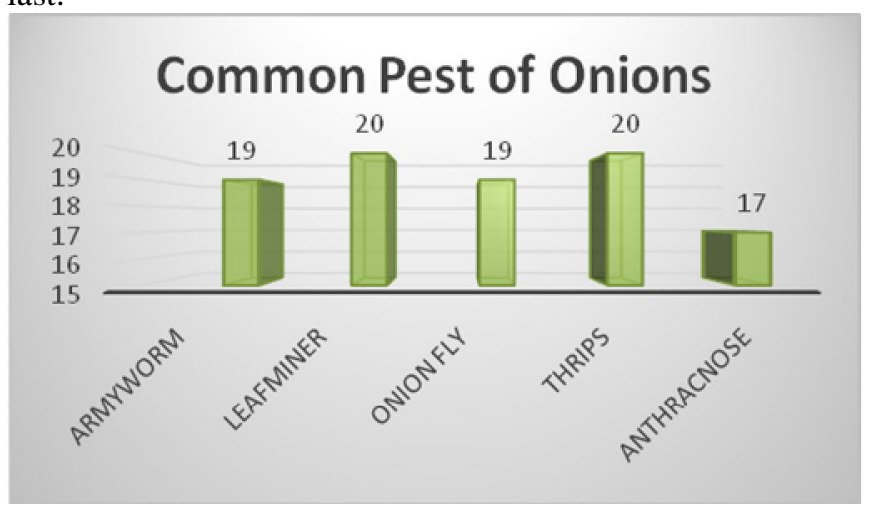

Figure 3: Common pests of onion

The most vulnerable stage of the onion growth is the 3rd stage where in the bulb initiation is involved being susceptible to all the insects and diseases while the 2nd stage is also as vulnerable as the 3rd stage only that this stage in not affected by Onion Fly. In addition, as the result shows, the 1st and 5th stage are not affected by any pest. Being only half the Maturation stage is affected by Anthracnose.

Linear regression was utilized in identifying the significant predictors in this study. Dependent variable includes the climatic data (temperature, humidity and precipitation), onion type and pest while the independent variable includes the weather forecast, suggested pesticide and prediction on pest occurrence. The derived equations are,

\section{Temperature:}

Armyworm: $\mathrm{Y}=0.075(\mathrm{t} 0)-0.109(\mathrm{t} 2)-0.130(\mathrm{t} 3)+4.45$, $\mathrm{r} 2=0.83$

Leafminer: $\mathrm{Y}=-0.131(\mathrm{t} 1)+3.514, \mathrm{r} 2=0.83$

Thrips: $\mathrm{Y}=0.075(\mathrm{t} 0)-0.109(\mathrm{t} 2)-0.130(\mathrm{t} 3)+4.45, \mathrm{r} 2=0.83$

Onion Fly: $\mathrm{Y}=0.124(\mathrm{t} 0)-0.174(\mathrm{t} 3)+1.461, \mathrm{r} 2=0.83$

Anthracnose: $\mathrm{Y}=-0.086(\mathrm{t} 2)-0.107(\mathrm{t} 4)-0.79(\mathrm{t} 5)+0.49(\mathrm{t} 7)$

$+6.042, \mathrm{r} 2=0.83$

Humidity:

Armyworm: $\mathrm{Y}=-0.091(\mathrm{~h} 0)+0.684(\mathrm{~h} 3)+0.744(\mathrm{~h} 5)+1.517$, $\mathrm{r} 2=0.15$

Leafminer: $\mathrm{Y}=0.638(\mathrm{~h} 2)-0.331, \mathrm{r} 2=0.15$

Thrips: $\mathrm{Y}=-0.091(\mathrm{~h} 0)+0.684(\mathrm{~h} 3)+0.744(\mathrm{~h} 5)+1.517$, r2 $=0.15$

Anthracnose: $\mathrm{Y}=0.827(\mathrm{~h} 1)-0.330, \mathrm{r} 2=0.15$

\section{Precipitation:}

Armyworm and Thrips Precipitation:

$\mathrm{Y}=0.076(\mathrm{p} 0)-0.220(\mathrm{p} 1)+3.945, \mathrm{r} 2=0.23$

As with the results, forecasting models were derived in predicting the major pest occurrence in onions. The equations are

The predictors per pest vary but the climatic data is the common predictor among them. In relation to pest occurrence, all pests are directly affected by the increase and decrease of temperature varying from the forecasted interval. The increase and decrease of humidity also affects the all pest occurrence except for Onion Fly which is also not affected by precipitation. Affected by precipitation are the Armyworm and Thrips only. As the findings suggest, the increase and decrease is directly proportional to the increase and decrease of all climatic changes both in the past and current climatic interval.

The Rete algorithm was primarily used for matching climatic data, as beta network or the dependent variable, and pest characteristics, as the alpha network or the independent variable. In accordance to the consequent formulated Retes Rules the algorithm PestMin $\leq$ Pest $\leq$ PestMax was derived thru the linear regression method in accordance with the survey study.

The derived linear regression equations, algorithms were incorporated in the developed mobile application in relation to farmers' inputs to create the prediction system OnionAider (short for onion aider). Figure 4 shows a sample screenshot from the developed application using Android Development Studio with Webview.

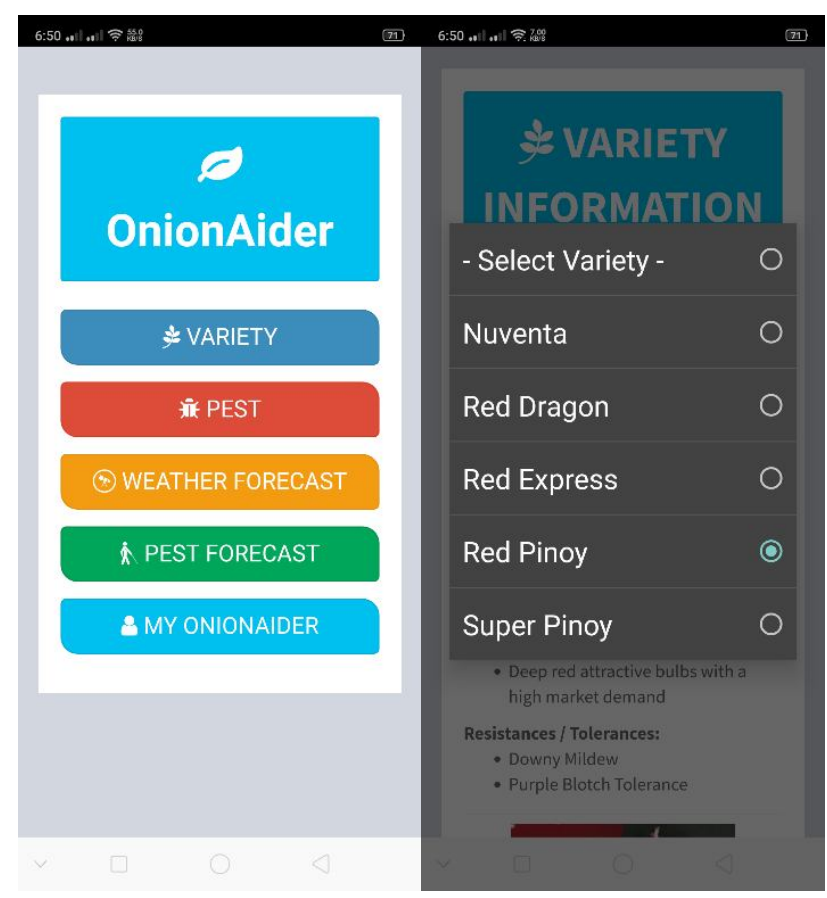

Figure 4: OnionAider main interface (Developed System) 
Fidel G. Patricio Jr et al., International Journal of Advanced Trends in Computer Science and Engineering, 9(3), May - June 2020, 3450 - 3453

Table 1 shows the summary of the extent of compliance as evaluated by the survey participants are in accordance with the ISO 25010 standards.IT Experts evaluated the software's function, output generated, multi-user capability and data access regulation giving these a qualitative description of Very Great Extent. These experts also gave the same qualitative description to the software's response time, execution time, performance efficiency, software's resources, ease of use, android compatibility, and browser compatibility. The IT experts gave a Very Great Extent qualitative description the systems ISO 25010 compliance in terms of its usability, reliability, security, maintainability and portability.

Table 1: The summary of extent of compliance in accordance with ISO 25010 standards

\begin{tabular}{|l|c|c|}
\hline \multicolumn{1}{|c|}{ COMPLIANCE } & MEAN & $\begin{array}{r}\text { QUALITATIVE } \\
\text { DESCRIPTION }\end{array}$ \\
\hline Functionality & 4.96 & Very Great Extent \\
\hline Efficiency & 4.92 & Very Great Extent \\
\hline Compatibility & 4.86 & Very Great Extent \\
\hline Usability & 4.86 & Very Great Extent \\
\hline Reliability & 4.83 & Very Great Extent \\
\hline Security & 4.86 & Very Great Extent \\
\hline Maintainability & 4.79 & Very Great Extent \\
\hline Portability & 2.92 & Little Extent \\
\hline \multicolumn{1}{|c|}{ OVERALL MEAN } & $\mathbf{4 . 6 3}$ & Very Great Extent \\
\hline
\end{tabular}

\section{CONCLUSION}

Based on the results obtained from the study, the following conclusions were made:

The mobile application features were found to be useful in predicting the pest occurrences. Additionally, the identification of pest predictors can help farmers adjust their cropping calendar in order to avoid the onslaught of onion pests. The system OnionAider was found to be compliant with the 25010 standards as evaluated by IT experts and system users.

\section{REFERENCES}

1. Allen, E. Precision pest control: smartphone app is the farmer's newest weapon in crop protection. Retrieved from https://phys.org/news/2019-01-precision-pest-smartpho ne-app-farmer.html, January 2019

2. Bautista N.M., Aquino Jr E.M. Community-based wide-scale strategic prevention and control of armyworm in the province of Nueva Ecija. DA-RCPCIII. Technical report. (2017)

3. B.Manoj, K.V.K.Sasikanth, M.V.Subbarao, V Jyothi Prakash. Analysis of Data Science with the use of Big Data, International Journal of Advanced Trends in Computer Science and Engineering, Volume 7, No.6, November - December 2019.

https://doi.org/10.30534/ijatcse/2018/02762018
4. Dalila B.M.M. Fontes, Paulo A. Pereira, Fernando A.C.C. Fontes. A Decision Support System for TV self-promotion Scheduling, International Journal of Advanced Trends in Computer Science and Engineering, Volume 8, No.2, March - April 2019. https://doi.org/10.30534/ijatcse/2019/06822019

5. Perante II, L. East-West Seed PHL projects sustainable onion industry nationwide. Retrieved from https://businessmirror.com.ph/2018/05/05/east-west-see d-phl-projects-sustainable-onion-industry-nationwidel, May 2018

6. Rabinowitch, H. D.; Currah, L. (2002). Allium Crop Sciences: Recent Advances. CABI Publishing. ISBN 978-0-85199-510-6. https://doi.org/10.1079/9780851995106.0000

7. Zaza, C., Bimonte, S., Faccilongo, N., La Sala, P., Contò, F., \& Gallo, C. A new decision-support system for the historical analysis of integrated pest management activities on olive crops based on climatic data. Computers \& Electronics in Agriculture, Chapter 148, pp 237-249. 2018

https://doi.org/10.1016/j.compag.2018.03.015 